\title{
Effects of farnesol and Iyticase on the formation of Candida albicans biofilm
}

\author{
Nadezhda Sachivkina1 ${ }^{(D)}$, Ekaterina Lenchenko² ${ }^{\mathbb{D}}$, Dmitri Blumenkrants², Alfia Ibragimova ${ }^{3}$ and \\ Olga Bazarkina ${ }^{4}$
}

1. Department of Microbiology and Virology, RUDN University, Miklukho Maklaya Street, 6, Moscow 117198, Russia; 2. Department of Veterinary Medicine, Moscow State University of Food Production, Volokolamskoe Highway, 11, Moscow 125080, Russia; 3. Department of Foreign Languages, Agrarian Technological Institute, RUDN University, Miklukho Maklaya Street, 6, Moscow 117198, Russia; 4. Department of Management and Economy in Pharmacy, Medical Institute, RUDN University, Miklukho Maklaya Street, 6, Moscow 117198, Russia.

Corresponding author: Nadezhda Sachivkina, e-mail: sachivkina@yandex.ru

Co-authors: EL: lenchenko.ekaterina@yandex.ru, DB: blumenkrants@inbox.ru,

AI: an99_63@mail.ru, OB: obazarkina@mail.ru

Received: 28-01-2020, Accepted: 27-04-2020, Published online: 08-06-2020

doi: www.doi.org/10.14202/vetworld.2020.1030-1036 How to cite this article: Sachivkina N, Lenchenko E, Blumenkrants D, Ibragimova A, Bazarkina O (2020) Effects of farnesol and lyticase on the formation of Candida albicans biofilm, Veterinary World, 13(6): 1030-1036.

\begin{abstract}
Background and Aim: Candida albicans is a dimorphic fungus that has both yeast and filamentous forms. It is part of the normal flora in the oral and genital areas of mammals. One factor for the pathogenicity of $C$. albicans is its ability to switch from yeast to hyphae. The hyphal form adheres and penetrates tissues more readily than the yeast form and produces biofilms that are associated with chronic infection. Biofilms are protective niches that enable microorganisms to be more resistant to antibiotic treatment, thus allowing for persistent infection. The first stage in the transition from yeast to hyphae involves the formation of a germ tube, and this transition is triggered by interactions with host cells. Germ tube formation is dependent on serum, $\mathrm{pH}$, temperature, and quorum-sensing molecules (QSMs). Farnesol, which is a QSM in C. albicans, can prevent yeast to hyphae conversion and inhibits the growth of fungal biofilm. Lyticase is a synergistic enzyme complex that catalyzes yeast cell lysis by $\beta$-1,3-glucanase and is a highly specific alkaline protease that produces protoplasts or spheroplasts. This study investigated the effect of farnesol and lyticase on the formation of C. albicans biofilms.
\end{abstract}

Materials and Methods: C. albicans ATCC 2091 was cultivated on liquid and solid Sabouraud media. The presence of C. albicans was confirmed using HiCrome Candida Agar chromogenic medium. Enzyme activities were assayed using a HiCandida Identification Kit. The morphology and densitometry parameters of $C$. albicans biofilms were considered in the presence of farnesol (Sigma-Aldrich, Germany), lyticase (from Arthrobacter luteus; Sigma-Aldrich, Germany), and farnesol-lyticase.

Results: This study shows that both farnesol and lyticase possess antifungal activity against C. albicans biofilms. A significant difference among treatment groups $(\mathrm{p}<0.05)$ was observed from strong biofilm production to medium and weak.

Conclusion: Many studies have been devoted to the antimicrobial action of farnesol. Bacterial enzyme lyticase is also used to degrade fungal cell walls. Both molecules show substantial antifungal properties that are similar to the properties of modern antimycotics. The current study demonstrates that farnesol and lyticase can disrupt biofilm formation in C. albicans ATCC 2091, which is an effective biofilm producer.

Keywords: antimycotic activity, biofilms, Candida albicans, enzyme activities, farnesol, hemolytic activity, HiCrome Candida Agar, lyticase, optical density, quorum sensing.

\section{Introduction}

Candida albicans causes disseminated infection in mammals and birds and is also a plant pathogen. It forms mono- and poly-species biofilms in clinical, industrial, and pharmaceutical circumstances [1,2].

The correlation of the morphology and densitometry observations of Candida spp. with the synthesis of intercellular matrix and the presence of planktonic

Copyright: Sachivkina, et al. Open Access. This article is distributed under the terms of the Creative Commons Attribution 4.0 International License (http://creativecommons.org/licenses/ by/4.0/), which permits unrestricted use, distribution, and reproduction in any medium, provided you give appropriate credit to the original author(s) and the source, provide a link to the Creative Commons license, and indicate if changes were made. The Creative Commons Public Domain Dedication waiver (http:// creativecommons.org/publicdomain/zero/1.0/) applies to the data made available in this article, unless otherwise stated. cells has been reported in pigs with endogenous infection and in dogs with acute and chronic forms of candidiasis $[3,4]$.

The virulence of Candida spp. is a function of adhesiveness, invasiveness, hydrolase production, and dimorphic switching (i.e., the morphological transition from yeast form to a mycelial form). Yeast morphology is required for dissemination, and mycelial morphology is needed for invasion [5-7]. The transcriptional control of adhesion, formation of biofilms, filamentation and production of extracellular polymeric substances, and ability to interact with other species in biofilms in vivo determine virulence, protection from immune response, and fungicidal drug resistance $[8,9]$.

The extracellular matrix, dimorphic growth, and presence of Candida spp. contribute to the increase in 
biomass of Clostridium perfringens and Bacteroides fragilis in cocultured biofilms. In the absence of fungi, bacterial viability decreases. A hyperfilamentous phenotype of C. albicans is characterized by high adhesion rates (more than ten-fold) and a significant decrease in dispersion [10]. The hyphal forms of Candida spp. provide a hypoxic microenvironment for yeast forms and for Escherichia coli [11].

Effective measures for the control and prevention of infectious diseases, including candidiasis, require finding effective antimycotic drugs that can reduce adhesion, disrupt intercellular information exchange, and block synthesis or destroy polymer matrices.

This research focuses on the correlation between the morphologic and densitometric indices of C. albicans biofilms and the administration of farnesol and lyticase.

\section{Materials and Methods}

\section{Ethical approval}

This study used a certified strain of $C$. albicans and does not require authorization from the ethics committee.

\section{Study period and location}

These experiments were conducted at the Department of Microbiology and Virology, RUDN University, and Department of Veterinary Medicine, Moscow State University of Food Production, between October 2019 and January 2020.

\section{Strain}

Standardized C. albicans strain ATCC 2091 BD Microtrol $^{\mathrm{TM}}$ was obtained. Before conducting experiments, the morphological, growth, and enzymatic characteristics were examined to demonstrate phenotypic stability [12].

Morphological and growth properties were observed on liquid and solid Sabouraud media (Biomerieux, France) with glucose, penicillin, and streptomycin $\left(100 \mathrm{ME} / \mathrm{L}\right.$ at $25^{\circ} \mathrm{C}, 37^{\circ} \mathrm{C}, 42^{\circ} \mathrm{C}$, and $45^{\circ} \mathrm{C}$ for $24 \mathrm{~h}$ ). The identity of $C$. albicans was confirmed using HiCrome Candida Agar chromogenic medium (HiMedia, India). Enzyme activities were measured using a HiCandida Identification Kit (HiMedia, India) containing urease, melibiose, lactose, maltose, sucrose, galactose, cellobiose, inositol, xylose, dulcitol, raffinose, and trehalose. Daily cultures of microorganisms with an optical density (OD) of 0.5 at a wavelength of $620 \mathrm{~nm}(0.5 \mathrm{OD}$ at $620 \mathrm{~nm})$ were added to $96-$ Well Microplates, MicroLiter and were cultured at $22.5^{\circ} \mathrm{C}$ for $48 \mathrm{~h}$.

Hemolytic activity used ready-made $5.0 \%$ blood agar with sheep erythrocytes (BioMedia, Russia). C. albicans culture was transferred to a nutrient medium, and the plates were incubated at $37^{\circ} \mathrm{C}$ for $24 \mathrm{~h}$. The appearance of clear halos around colonies ( $\alpha$-hemolysis), the greening of the broth ( $\beta$-hemolysis), or the absence of color ( $\gamma$-hemolysis) was recorded.

The presence of chlamydospores was assessed in terms of growth after the transfer of cells incubated for
$24 \mathrm{~h}$ in Sabouraud medium on rice agar (API-System R.A.T., France) and after cultivation at $25^{\circ} \mathrm{C}$ for 24 $\mathrm{h}$. The formation of hyphal germ tubes was assessed in cells cultured in $1.0 \mathrm{ml}$ meat peptone broth (MPB) supplemented with bovine blood serum (Microgen, Russia) at $37^{\circ} \mathrm{C}$ for $5 \mathrm{~h}$.

The morphological and densitometry of biofilms were considered after treatment with farnesol (SigmaAldrich, Germany), lyticase (from Arthrobacter luteus; Sigma-Aldrich, Germany), and farnesol+lyticase.

Control studies used MPB (nutrient broth, HiMedia, India). C. albicans was grown in nutrient broth at $37^{\circ} \mathrm{C}$ for $48 \mathrm{~h}$ for experiments I-IV:

- I: Culture of C. albicans, 4 (McFarland)

- II: Culture of C. albicans, 4 (McFarland), farnesol, $100-400 \mu \mathrm{M}$

- III: Culture of C. albicans, 4 (McFarland), lyticase, 250-1000 units

- IV: Culture of C. albicans, 4 (McFarland), farnesol+lyticase.

For microscopic examination, C. albicans was cultivated on glass slides placed in Petri dishes with $20.0 \mathrm{ml}$ MPB and $5.0 \mathrm{ml}$ of an $18 \mathrm{~h}$-old culture at a concentration of $105 \mathrm{CFU} / \mathrm{ml}$ at $37^{\circ} \mathrm{C}$ for $48 \mathrm{~h}$. Test samples were fixed with a mixture of alcohol-ether (1:1) for $10 \mathrm{~min}$ and stained with a $0.5 \%$ methylene blue [13-15]. The absence of yeast and mycelial forms was determined by microscopy using an optical microscope "BioMed MC-1 Stereo" (Russia). A representative sample showed a frequency of occurrence of $\geq 90.0 \%$.

The OD of biofilms was measured by the degree of binding of crystal violet (HiMedia, India) at a wavelength of $580 \mathrm{~nm}$ (OD580) in an Immunochem-2100 microplate photometric analyzer (HTI, USA). The samples were added to the wells of a 96-well plate (Medpolymer, Russia) and were cultured at $37^{\circ} \mathrm{C}$ for $48 \mathrm{~h}$. Liquid was removed, and wells were washed 3 times with $200 \mu \mathrm{l}$ of phosphate-buffered saline solution ( $\mathrm{pH}$ 7.3). At each washing step, the plates were shaken for $5 \mathrm{~min}$. Biofilms were fixed in $150 \mu \mathrm{l}$ of $96.0 \%$ ethanol for $15 \mathrm{~min}$, and wells were dried at $37^{\circ} \mathrm{C}$ for $20 \mathrm{~min}$. Biofilms were stained with a $0.5 \%$ solution of crystal violet at $37^{\circ} \mathrm{C}$ for $5 \mathrm{~min}$. The liquid was removed from wells, and the wells were rinsed 3 times with $200 \mu \mathrm{l}$ of phosphate-buffered saline solution $(\mathrm{pH} 7.3)$ and then dried. Dye was eluted from adherent cells with $200 \mu \mathrm{l}$ of $96.0 \%$ ethanol for $30 \mathrm{~min}$ [5]. Biofilm formation was differentiated by the intensity of biofilm staining:

- $\mathrm{OD}_{\mathrm{s}} \leq \mathrm{OD}_{\mathrm{c}}$ : Microorganisms that do not produce biofilm

- $\mathrm{OD}_{\mathrm{c}}<\mathrm{OD}_{\mathrm{s}} \leq\left(2 \times \mathrm{OD}_{\mathrm{c}}\right)$ : Low active biofilm producers

- $\left(2 \times \mathrm{OD}_{\mathrm{c}}\right)<\mathrm{OD}_{\mathrm{s}} \leq\left(4 \times \mathrm{OD}_{\mathrm{c}}\right):$ Moderate biofilm producers

- $\left(4 \times \mathrm{OD}_{\mathrm{c}}\right)<\mathrm{OD}_{\mathrm{s}}$ : Potent biofilm producers, where ODc - optical density of control; ODs optical density of sample. 


\section{Statistical analysis}

Experimental data were processed using descriptive and inferential statistics. The means and standard deviations of optical densities and adhesive properties were calculated using Microsoft Excel. The differences between the means of the test samples and controls were assessed using Student's t-test, and statistical significance was set at $\mathrm{p} \leq 0.05$.

\section{Results}

\section{Culturing of yeast like fungi and biochemical test}

C. albicans showed a typical round or oval yeast shape with a diameter of $1.5-10 \mu \mathrm{m}$, and these properties differentiated them from chlamydospores and pseudomycelia. Spherical chlamydospores that were formed by the rounding of terminal filamentous hyphae were seen on native preparations without staining. These chlamydospores had diameters of 7.0$13.0 \mu \mathrm{m}$. The filaments of pseudohyphae had no common membrane or septum and were pressed tightly together. The microscopic images of smears stained with methylene blue revealed seedling tubes, which are the precursors of true hyphae. Microorganisms produced turbidity and formed precipitates and films while growing in nutrient broth. On Sabouraud agar with glucose at $25^{\circ} \mathrm{C}$, Candida formed smooth, convex, white, soft, and consistent colonies. Growth was also observed at $37^{\circ} \mathrm{C}, 42^{\circ} \mathrm{C}$, and $45^{\circ} \mathrm{C}$ (Table-1).

The studied strain displayed the typical phenotypic characteristics described in the Guide to Clinically Significant Fungi by Deanna A. Sutton (2001).

\section{Optical microscopy}

C. albicans grown at $37^{\circ} \mathrm{C}$ for $48 \mathrm{~h}$ (experiment I) showed dimorphic fungal growth, adherence to substrate (glass) in heterogeneous structures, vegetative yeast forms, blastospores and hyphae forms, hyphae, and pseudohyphae. Yeast forms were stained intensely blue and elongated hyphae, pseudohyphae, and communicating filaments were also stained with blue. Blastospores were located on the hyphae. Blue chlamydospores with a double membrane were observed on the terminal extensions of the hyphae. The blue and deep blue aggregations of the heterogeneous structures of yeast and hyphae forms were connected by a layer of intercellular matrix (Figure-1).

A biofilm develops through the adhesion, fixation, and synthesis of extracellular polymeric substances that enable intercellular communication. Nutrients accumulate in the population as cells proliferate. An increase in cell population leads to an increase in the density of the extracellular matrix. An increasingly compact matrix "cements" yeast and mycelial forms into branched, separate, round, or oval structures. These structures are separated by matrix voids and are probably filled with liquid.

The heterogeneous structure of the fungal population in this study consisted of yeast forms, hyphal germ tubes, and short hyphae (Figure-2). Microcolonies were presented with aggregates of yeast forms, fermentation tubes, and short hyphae and were combined in a basal layer surrounded by an intercellular polymer matrix. The stable architecture of the 3D biofilm progressed to the coaggregation of yeast and mycelial forms combined with an extracellular matrix. Long-branched hyphal forms were composed of dense pseudomycelial structures (Figure-3). At the center of the oval microcolonies, the matrix became prominent with the absence of separate cells. In the periphery of colonies, the extracellular matrix gradually thinned, and individual cells were arranged in orderly concentric rows.

In areas of thinning, the population was unstructured, and cells displayed different sizes and shapes. Dispersion regions were observed at the periphery

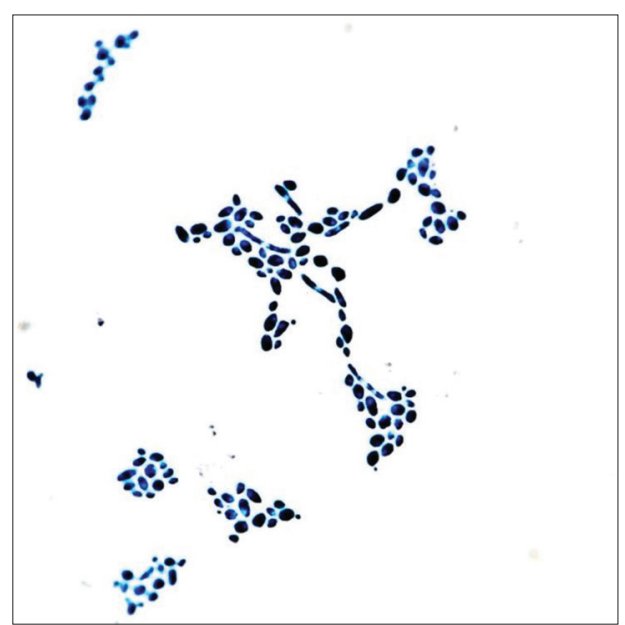

Figure-1: The intensity of Candida albicans biofilms, $37^{\circ} \mathrm{C}$ $48 \mathrm{~h}$ - experiment (I): Yeast and mycelial forms forming the aggregation of microorganisms, covered by a thin layer of blue intercellular matrix. Staining with a methylene blue, optical microscopy $200 x$.

Table-1: Phenotypic characteristics of Candida albicans.

\begin{tabular}{|c|c|c|c|c|}
\hline \multirow{2}{*}{$\begin{array}{l}\text { Morphological } \\
\text { characteristics }\end{array}$} & \multicolumn{4}{|c|}{ Colony characteristics } \\
\hline & $\begin{array}{l}\text { Sabouraud dextrose } \\
\text { broth }\end{array}$ & $\begin{array}{l}\text { Sabouraud } \\
\text { dextrose agar }\end{array}$ & $\begin{array}{l}\text { HiCrome } \\
\text { candida agar }\end{array}$ & Hemolytic activities \\
\hline $\begin{array}{l}\text { Spherical or oval yeast } \\
\text { chlamydospores hyphae } \\
\text { pseudohyphae hyphal germ } \\
\text { tubes }\end{array}$ & $\begin{array}{l}\text { Microfluid opacity, } \\
\text { membrane, incoherent } \\
\text { precipitate }\end{array}$ & $\begin{array}{l}\text { Smooth, convex, } \\
\text { white, soft texture }\end{array}$ & $\begin{array}{l}\text { Colonies of a } \\
\text { light-green color }\end{array}$ & $\gamma$-hemolysis \\
\hline
\end{tabular}

\begin{tabular}{|c|c|c|c|c|c|}
\hline Enzyme & & & & & \\
\hline Urease & Melibiose & Lactose Maltose & Sucrose Galactose Cellobiose & Inositol Xylose & Dulcitol Raffinose Trehalose \\
\hline- & - & + & + & - & - \\
\hline
\end{tabular}


of microcolonies. This stage is characterized by the destruction of the intercellular matrix and the subsequent separation of "daughter" yeast cells in branched structures for the colonization of a free substrate (Figure-4).

After exposure to antimycotic agents (experiments II and III), cultures were characterized by the presence of yeast forms, and coadhesive properties

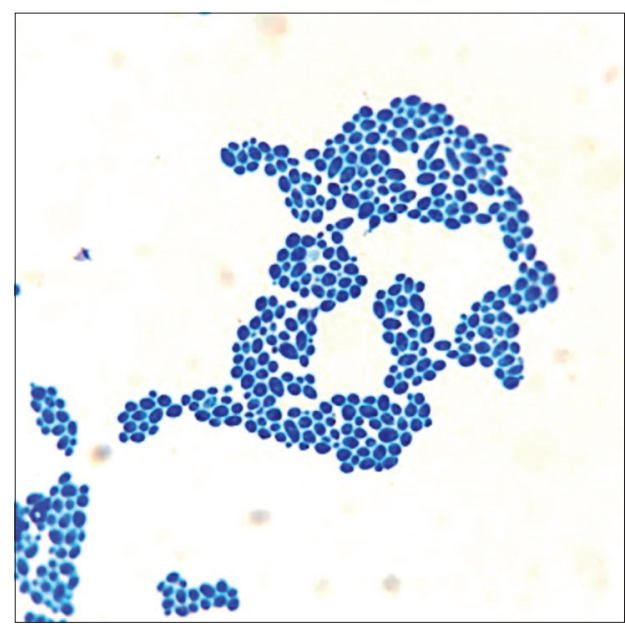

Figure-2: The intensity of the formation of biofilms of Candida albicans, $37^{\circ} \mathrm{C} 48 \mathrm{~h}$ - experience (I): Isolated structures separated by matrix voids. Staining with a methylene blue, optical microscopy $200 x$.

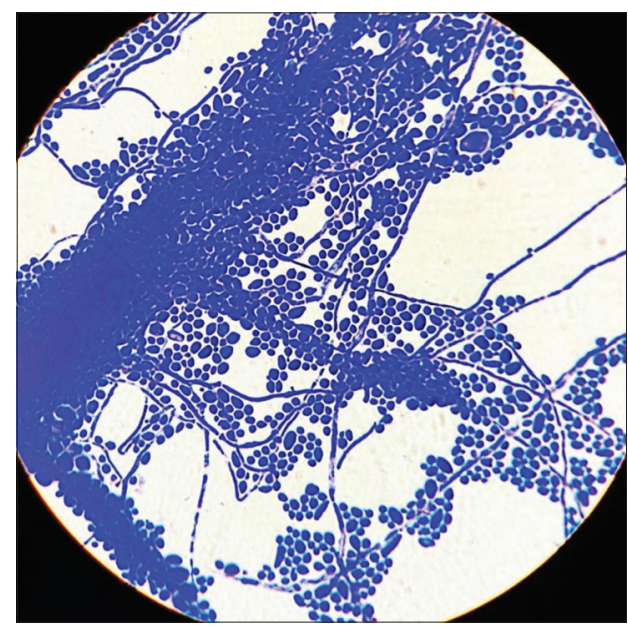

Figure-3: The intensity of the formation of biofilms of Candida albicans, $37^{\circ} \mathrm{C} 48 \mathrm{~h}$ - experiment (I): Architectonics of a grown biofilm. Coaggregation of yeast and mycelial forms is combined with an exocellular matrix. The long branched hyphal forms are composing dense structures from pseudomycelia. Staining with a methylene blue, optical microscopy $100 \times$. were impaired. Hyphal growth was significantly reduced or absent. Single cells had an angular shape, and hyphae were short and collapsed.

Changes in the colony structure of $C$. albicans biofilms were evaluated by the presence ("+") or absence ("-") of yeast and mycelial forms (Table-2). A representative sample showed a reliability of $\geq 90.0 \%$ for the observed fields.

- Experiment I: Coaggregation of yeast and mycelial forms combined by extracellular matrix and long-branched hyphal forms and formation of dense structures from pseudomycelia

- Experiment II-III: Microcolonies

- Experiment IV: Single cells and clusters.

\section{Densitometric values}

Indicators of $\mathrm{OD}$ in experiment I: $\mathrm{An} \mathrm{OD}_{\mathrm{s}}$ of $5.03 \pm 0.06$ for $C$. albicans incubated under our standard conditions exceeded the control index $\mathrm{OD}_{\mathrm{c}}$ of $0.098 \pm 0.09$ more than five-fold. These cells produced substantial biofilm (Table-3). In experiment II, the ODs for cells treated with farnesol $(0.382 \pm 0.16)$ exceeded the control OD of $0.098 \pm 0.09$ by less than four-fold, thus indicating moderate biofilm production (Table-4). Similarly, for experiment III, the ODs for cells treated with lyticase $(0.284 \pm 0.08)$ exceeded the control $\mathrm{OD}_{\mathrm{c}}(0.099 \pm 0.08)$ by less than three-fold, thus indicating moderate biofilm production (Table-5). In the presence of both farnesol and lyticase, $\mathrm{OD}_{\mathrm{s}}$

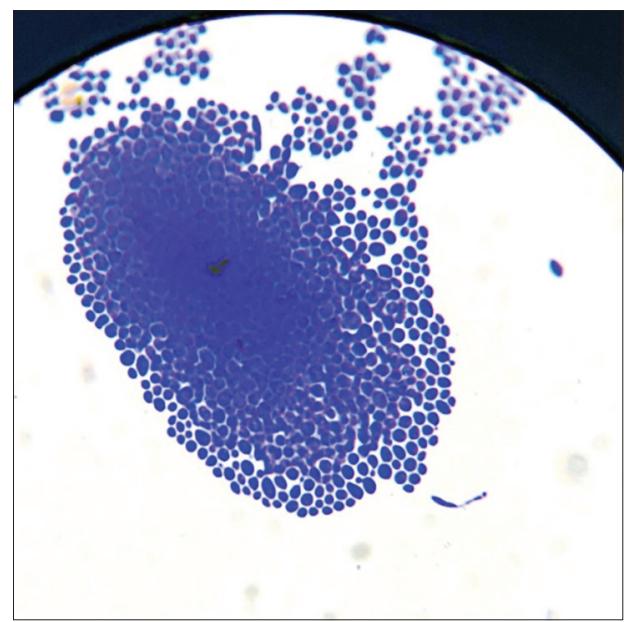

Figure-4: The intensity of the formation of Candida albicans biofilms, $37^{\circ} \mathrm{C} 48 \mathrm{~h}$ - experiment (I): Microcolony - coaggregation of microorganisms united by an exocellular matrix more pronounced in the central part and much thinner on the periphery. Staining with a methylene blue, optical microscopy $100 x$.

Table-2: Changes in the colony of Candida albicans biofilms after exposure to antifungal drugs.

Groups
Changes in the colony structures $(\geq 90.0 \%$ in the microscope POV)

Solitary cells and clusters Microcolonies Mycelial forms

I - C. albicans

II - C. albicans - Farnesol, $400 \mu \mathrm{M}$

III - C. albicans - Lyticase, 1000 units

IV - C. albicans - Farnesol $400 \mu \mathrm{M}$ - Lyticase, 1000 units

$\begin{array}{lll}+ & + & + \\ + & - & - \\ + & - & - \\ + & - & -\end{array}$

+ - presence, - - absence. Candida albicans $=C$. albicans 
$(0.196 \pm 0.06)$ exceeded the control $\mathrm{OD}_{\mathrm{c}}(0.098 \pm 0.12)$ by approximately two-fold, thus indicating weak biofilm production (Table-6).

C. albicans exposed to antimycotic agents showed parallel changes in morphometric (\%) and densitometry indicators $\left(\mathrm{OD}_{\mathrm{s}}\right)$. The changes included reduced frequency of clusters and OD. The frequency of clusters, which is defined as the aggregation of microorganisms united by a thin layer of intercellular matrix, significantly decreased from high cluster frequency in experiment I to moderate cluster frequency in the presence of farnesol (experiment II) or lyticase (experiment III). The combination of farnesol and lyticase (experiment IV) led to the low cluster frequency.

\section{Discussion}

Our research, along with the previous reports, indicates that various taxonomic groups display common patterns of biofilm formation: Adhesion, fixation, maturation, growth, and dispersion [13]. The biosynthesis of exopolysaccharides is accompanied by a decrease in metabolic activity and the transformation of microbial populations to an "uncultivated condition" [14]. The morphofunctional stability of C. albicans biofilms is based on yeast and hyphal forms, and the process of seedling formation ensures the development of the intercellular matrices [15].

The adsorption, adhesion, and fixation of basal yeast layers, along with the early development of hyphae and matrix, contribute to the increased biomass of yeast, hyphae, pseudohyphae, extracellular matrix, and water channels. These structures promote the movement of nutrients and the dissemination of cells. Furthermore, filamentation is directly associated with the increased density of Candida spp. biofilms [16]. The formation of a heterogeneous structure of $C$. albicans biofilms is a multistage process. A 3D biofilm structure was detected after 38-72 h. The

Table-3: Analysis of the optical density of biofilms.

\begin{tabular}{|c|c|c|c|c|}
\hline \multirow[t]{2}{*}{ Microorganism culture } & \multicolumn{4}{|c|}{ Optical density (OD) } \\
\hline & Control $\left(O D_{c}\right)$ & $\operatorname{Exp}\left(O D_{s}\right)$ & $\Delta\left(O D_{s}-O D_{c}\right)$ & Intensity (I) \\
\hline Candida albicans & $0.099 \pm 0.03$ & $0.503 \pm 0.06$ & $0.404 \pm 0.09$ & $\geq 0.4$ \\
\hline \multicolumn{5}{|c|}{$\begin{array}{l}\leq 0.1-\text { non-biofilm producing microorganisms, } \leq 0.2-\text { weak biofilm producers, } \leq 0.3-\text { medium biofilm producers, } \geq 0.4- \\
\text { strong biofilm producers }\end{array}$} \\
\hline \multirow[t]{2}{*}{ Medicine concentration, $\mu \mathrm{M}$} & \multicolumn{4}{|c|}{ Optical density (OD) } \\
\hline & Control $\left(O D_{c}\right)$ & $\operatorname{Exp}\left(O D_{s}\right)$ & $\Delta\left(O D_{s}-O D_{c}\right)$ & Intensity (I) \\
\hline 100 & $0.096 \pm 0.03$ & $0.395 \pm 0.06$ & $0.299 \pm 0.09$ & $\leq 0.3$ \\
\hline 200 & $0.099 \pm 0.05$ & $0.372 \pm 0.03$ & $0.273 \pm 0.08$ & $\leq 0.3$ \\
\hline 400 & $0.098 \pm 0.01$ & $0.365 \pm 0.07$ & $0.267 \pm 0.09$ & $\leq 0.3$ \\
\hline
\end{tabular}

$\leq 0.1$ - non-biofilm producing microorganisms; $\leq 0.2$ - weak biofilm producers; $\leq 0.3$ - medium biofilm producers; $\geq 0.4$ strong biofilm producers

Table-5: Analysis of the optical density of biofilms of microorganisms when exposed to the Lyticase.

\begin{tabular}{|c|c|c|c|c|}
\hline \multirow[t]{2}{*}{ Medicine concentration, units } & \multicolumn{4}{|c|}{ Optical density (OD) } \\
\hline & Control $\left(O D_{c}\right)$ & $\operatorname{Exp}\left(O D_{s}\right)$ & $\Delta\left(O D_{s}-O D_{c}\right)$ & Intensity (I) \\
\hline 250 & $0.099 \pm 0.08$ & $0.371 \pm 0.09$ & $0.272 \pm 0.17$ & $\leq 0.3$ \\
\hline $\begin{array}{l}500 \\
1000\end{array}$ & $\begin{array}{l}0.096 \pm 0.02 \\
0.098 \pm 0.09\end{array}$ & $\begin{array}{l}0.335 \pm 0.01 \\
0.299 \pm 0.05\end{array}$ & $\begin{array}{l}0.239 \pm 0.03 \\
0.201 \pm 0.14\end{array}$ & $\begin{array}{l}\leq 0.3 \\
\leq 0.3\end{array}$ \\
\hline
\end{tabular}

$\leq 0.1$ - non-biofilm producing microorganisms, $\leq 0.2$ - weak biofilm producers, $\leq 0.3$ - medium biofilm producers, $\geq 0.4-$ strong biofilm producers

Table-6: Analysis of the optical density of biofilms of microorganisms when exposed to the Farnesol and Lyticase.

\begin{tabular}{|c|c|c|c|c|}
\hline \multirow[t]{2}{*}{ Medicine concentration, $\mu \mathrm{M}$ - Farnesol units - Lyticase } & \multicolumn{4}{|c|}{ Optical density (OD) } \\
\hline & Control $\left(O D_{c}\right)$ & $\operatorname{Exp}\left(O D_{s}\right)$ & $\Delta\left(O D_{s}-O D_{c}\right)$ & Intensity (I) \\
\hline $\begin{array}{l}100 \\
250\end{array}$ & $0.099 \pm 0.02$ & $0.259 \pm 0.09$ & $0.160 \pm 0.11$ & $\leq 0.2$ \\
\hline $\begin{array}{l}200 \\
500\end{array}$ & $0.098 \pm 0.04$ & $0.219 \pm 0.01$ & $0.121 \pm 0.05$ & $\leq 0.2$ \\
\hline $\begin{array}{l}400 \\
1000\end{array}$ & $0.098 \pm 0.07$ & $0.200 \pm 0.06$ & $0.102 \pm 0.09$ & $\leq 0.2$ \\
\hline
\end{tabular}

$\leq 0.1$ - non-biofilm producing microorganisms, $\leq 0.2$ - weak biofilm producers, $\leq 0.3$ - medium biofilm producers, $\geq 0.4$ strong biofilm producers 
biofilm consisted of a dense network of yeast cells, hyphae, and pseudohyphae surrounded by an intercellular polymer matrix $[3,17]$.

Among the 47 Candida spp. isolates, the most common polymorphism primer is OPA 9. The similarity coefficients reached $95.0 \%$ for six clusters, including C. albicans from vaginal infections. The dispersion of cells from a cluster is the result of shifting that is unrelated to the dispersion caused by a transcription regulator signal [8].

The destruction of the cell wall and the extraction of $C$. albicans DNA are 90 min faster when exposed to recombinant lyticase, and this can be accomplished with mechanical disruption using glass beads $[18,19]$. Lyticase caused a decrease in OD to $53.0 \%$, a decrease in adhesion to epithelial cells, and an inhibition of mycelial growth [20,21]. Xylitol (10.0\%) and sodium alginate $(4.16 \%)$ suppressed the virulence of C. albicans by preventing the formation of hyphal forms and by reducing biofilm density to $47.0-52.0 \%$ [14].

When exposed to increasing farnesol concentrations $(0,3,30$, and $300 \mu \mathrm{M})$, morphological transition from yeast to hyphal forms was prevented at the highest concentration[22]. When exposed to farnesol at concentrations of $1-50 \mu \mathrm{mM}$, a decrease in the pathogenicity of $C$. albicans was noted due to the inhibition of hyphae formation. This inhibitory effect of farnesol was accompanied by a significant increase in culture density, accumulation on cell surfaces, and downregulation of proteins that determine the structural organization of biofilms [23,24]. Farnesol regulates the specific components of signal transmission and transcription, thus inhibiting the hyphal growth of the hyphae of $C$. albicans, affecting the interaction of mRNA with the small ribosomal subunit, and leading to a decrease in the level of the initiating ribosomal complex [15].

Farnesol inhibited the formation of $C$. albicans mycelium but did not reduce the growth of hyphal germ tubes. At a concentration of $450.0 \mu \mathrm{M}$, farnesol inhibited biofilm formation by $35.0 \%$ [16]. Farnesol $(300.0 \mu \mathrm{M})$ inhibited the transition of yeast to the hyphal form. Furthermore, due to a decrease in the expression of Sap2 and Sap4-Sap6, the shape of the cells was changed, cell wall integrity was impaired, and increased granulation of the cytoplasm was induced with the presence of large vacuoles [24]. A significant decrease $(56.2 \%)$ in the biomass of C. albicans biofilms was observed at a $12.5 \%$ concentration of farnesol. It was found that the presence of the transcription factor "TEC1" protects the biofilm from drug diffusion $[25,26]$.

\section{Conclusion}

We show the coaggregation of yeast and mycelial forms that is united by an exocellular matrix, longbranched hyphal forms, and dense structures formed by pseudomycelia. When exposed to antimycotic agents, cultures were characterized by the predominant presence of yeast forms, impaired coadhesion, and reduced or absent hyphal growth. Single cells displayed an angular shape, and hyphae were short and collapsed. The frequency of clusters united by a thin layer of intercellular matrix significantly decreased in the following order: C. albicans (experiment I), prominent biofilm production; farnesol (experiment II) and lyticase exposed cells (experiment III), moderate biofilm production; and farnesol and lyticase (experiment IV), low biofilm production.

\section{Authors' Contributions}

NS and EL had the original idea for the study and carried out the design. DB collected the samples. AI was responsible for data analysis and data cleaning. EL, OB, and NS drafted the manuscript. The final draft manuscript was revised by all authors. All authors edited, read, and approved the final manuscript.

\section{Acknowledgments}

The authors would like to thank the Moscow State University of Food Production and Peoples' Friendship University of Russia (RUDN University) for providing the facilities to carry out the research work. The authors did not receive any funds for this study.

\section{Competing Interests}

The authors declare that they have no competing interests.

\section{Publisher's Note}

Veterinary World remains neutral with regard to jurisdictional claims in published institutional affiliation.

\section{References}

1. Cavalheiro, M. and Teixeira, M. (2018) Candida biofilms: Threats, challenges, and promising strategies. Front Med., 28(5): 1-15.

2. Sachivkina, N.P., Lenchenko, E.M., Mannapova, R.T., Strizhakov, A.A., Romanova, E.V. and Lukina, D.M. (2019) Candida biofilm modeling: Past and present. Farmatsiya, 68(3): 18-22.

3. Chandra, J., Kuhn, D.M., Mukherjee, P.K., Hoyer, L.L., McCormick, T. and Ghannoum, M.A. (2001) Biofilm formation by the fungal pathogen Candida albicans: Development, architecture, and drug resistance. J. Bacteriol., 183(18): 5385-5394.

4. Sachivkina, N., Lenchenko, E., Strizakov, A., Zimina, V., Gnesdilova, L., Gavrilov, V., Byakhova, V., Germanova, S., Zharov, A. and Molchanova, M. (2018) The Evaluation of formation of biomembrane by microscopic Fungi of the Candida genus. Int. J. Pharm. Res., 10(4): 738-744.

5. Lenchenko, E., Blumenkrants, D., Sachivkina, N., Shadrova, N. and Ibragimova, A. (2020) Morphological and adhesive properties of Klebsiella pneumoniae biofilms. Vet. World, 13(1): 197-200.

6. Lenchenko, E., Lozovoy, D., Strizhakov, A., Vatnikov, Y., Byakhova V., Kulikov, E., Sturov, N., Kuznetsov, V., Avdotin, V. and Grishin, V. (2019) Features of formation of Yersinia Enterocolitica biofilms. Vet. World, 12(1): 136-140.

7. Sachivkina, N.P., Karamyan, A.S., Kuznetsova, O.M., 
Byakhova, V.M., Bondareva, I.B. and Molchanova M.A. (2019) Development of therapeutic transdermal systems for microbial biofilm destruction. FEBS Open Bio, 9(S1): 386.

8. Kaneko, Y., Miyagawa, S., Takeda, O., Hakariya, M., Matsumoto, S., Ohno, H. and Miyazaki, Y. (2013) Real-time microscopic observation of Candida biofilm development and effects due to micafungin and fluconazole. Antimicrob. Agents Chemother., 57(5): 2226-2230.

9. Lenchenko, E.M., Vatnikov, Y.A., Kulikov, E.V., Lozovoy, D.A., Gavrilov, V.A., Gnezdilova, L.A., Zimina, V.N., Kuznetsov, V.I., Annikov, V.V., Medvedev, I.N., Petryaeva, A.V. and Glagoleva, T.I. (2019) Aspects of Salmonellosis pathogenesis using chicken models. Bali Med. J., 8(1): 206-210.

10. McCall, A.D., Pathirana, R.U. and Prabhakar A. (2019) Candida albicans biofilm development is governed by cooperative attachment and adhesion maintenance proteins. NPJ Biofilms Microbiomes, 21(5): 94-95.

11. Sachivkina, N.P., Lenchenko, E.M. and Marakhova, A.I. (2019) Study of the formation of Candida albicans and Escherichia coli biofilms. Farmatsiya, 68(7): 26-30.

12. Satton, D., Fothergill, A. and Rinaldi, M. (2001) Identification of Pathogenic and Opportunistically Pathogenic Fungi. Russian Translation Mir, Moskow.

13. Lenchenko, E.M., Khai, F.W., Vatnikov, Y.A. and Abdullaeva, A.M. (2019) The study of the sensitivity of Salmonella to antibacterial drugs. Int. Bull. Vet. Med., 2(1): 55-61.

14. Grammatikova, N.E., Vasilenko, I.A., Ambrosov, I.A. and Matelo, S.K. (2014) Inhibition of formation of biofilms and hyphal forms of Candida albicans treated with medications based on xylitol and sodium alginate in experiments in vitro. Dev. Regist. Med., 7(2): 132-137.

15. Carreiro, A.P., Guedes, S.F., Panariello, B.H., Silveira, P.V. and Janal, M.N. (2017) Farnesol anti-biofilm activity against Candida albicans reference and mutant strains. Microb. Res. J. Int., 22(6): 1-7.

16. Décanis, N., Tazi, N., Correia, A., Vilanova, M. and Rouabhia M. (2011) Farnesol, a fungal quorum-sensing molecule triggers Candida albicans morphological changes by downregulating the expression of different secreted aspartyl proteinase genes. Open Microbiol. J., 5(1): 119-126.

17. Fox, E.P., Cowley, E.S., Nobile, C.J., Hartooni, N., Newman, D.K and Johnson A.D. (2014) Anaerobic Bacteria grow within Candida albicans biofilms and induce biofilm formation in suspension cultures. Curr. Biology., 24(20): 2411-2416

18. Scott, J.H. and Schekman, R. (1980) Lyticase: Endoglucanase and protease activities that act together in yeast cell lysis. J. Bacteriol., 142(2): 414-423.

19. Sachivkina, N.P., Kravtsov, E.G., Vasilyeva, E.A., Anokhina, I.V. and Dalin, M.V. (2009) Study of antimycotic activity of lyticase. Bull. Exp. Biol. Med., 148(2): 214-216.

20. Morozov, I.A., Sachivkina, N.P., Kravtsov, E.G., Vasilyeva, E.A., Anokhina, I.V., Yashina, N.V. and Dalin, M.V. (2011) Damaging effects of lyticase on Candida albicans and changes in the response of rat alveolar macrophages to the contact with yeast-like fungi. Bull. Exp. Biol. Med., 151(6): 705-708.

21. Sachivkina, N.P., Kravtsov, E.G., Vasileva, E.A., Anokchina, I.V. and Dalin, M.V. (2010) Efficiency of lyticase (bacterial enzyme) in experimental candidal vaginitis in mice. Bull. Exp. Biol. Med., 149(6): 727-730.

22. Egbe, N.E., Dornelles, T.O., Paget, C.M., Castelli, L.M. and Ashe, M.P. (2017) Farnesol inhibits translation to limit growth and filamentation in C. albicans and S. cerevisiae. Microb. Cell, 9(4): 294-304.

23. Martins, M., Henriques, M., Azeredo, J., Rocha, S.M., Coimbra, M.A. and Oliveira R. (2007) Morphogenesis control in Candida albicans and Candida dubliniensis through signaling molecules produced by planktonic and biofilm cells. Eukaryot. Cell, 12(6): 2429-2436.

24. Mosel, D.D., Dumitru, R., Hornby, M.J., Atkin, A.L. and Nickerson K.W. (2005) Farnesol concentrations required to block germ tube formation in Candida albicans in the presence and absence of serum. Appl. Environ. Microbiol., 71(8): 4938-4940.

25. Ramage, G., Saville, S.P., Wickes, B.L. and LópezRibot, J.L. (2002) Inhibition of Candida albicans biofilm formation by farnesol, a quorumsensing molecule. Appl. Environ. Microbiol., 68(11): 5459-5463.

26. Rudenko, P., Rudenko, V., Vatnikov, Y., Rudenko, A., Kulikov, E., Sachivkina, N., Sotnikova, E., Sturov, N., Rusanova, E., Mansur, T., Vyalov, S., Sakhno, N., Drukovsky, S. (2020) Biocoenotic Diagnostics of Unfavorable Factors in the Cows Infection of Farms in the Moscow Region. Syst. Rev. Pharm., 11(5): 347-357. 